\title{
Single stage repair for aortic root aneurysm in a patient with coexisting coarctation incorporating the Cabrol technique: a case report
}

\author{
Yassir lqbal ${ }^{1}$, Omar A. Jarral ${ }^{2,4^{*}}$, Pantelis Tsipas ${ }^{3}$, llias Samiotis ${ }^{3}$, Theodoros Kratimenos ${ }^{3}$, John Kokotsakis ${ }^{3}$ \\ and Thanos Athanasiou ${ }^{2}$
}

\begin{abstract}
Background: A 44 year old man who presented with a history of chest pain and dyspnoea was found to have an aneurysm of the aortic root, aortic valve insufficiency, and coarctation of the aorta.

Case presentation: The patient underwent a single stage procedure to treat the aortic root, valve and coarctation with a composite valved conduit and extra-anatomic bypass of the coarctation. The modified Cabrol technique was necessary to attach the coronary buttons due to grossly abnormal anatomy. The patient made a remarkable recovery and was discharged on the 8th post-operative day.

Conclusion: This case report highlights the feasibility and efficacy of performing a single stage procedure on complex coarctation with associated cardiac defects. To the best of our knowledge, this is the first report of the modified Cabrol technique being used in this particular setting.
\end{abstract}

Keywords: Aortic Coarctation, Aortic root aneurysm, Extra-anatomical bypassCabrol

\section{Background}

Aortic coarctation is a relatively common congenital abnormality. The prevalence accounts for $6-8 \%$ of all live births with congenital heart defects. It occurs at the isthmus of the aorta (distal aortic arch between the left subclavian and the site of the ligamentum arteriosus) where there is a discrete narrowing [1].

Patients with associated arch hypoplasia are at increased risk of developing hypertension. They have an increased incidence of acute cardiac events and delayed aneurysm and dissection formation even following correction [2]. There has been much debate as to the optimum surgical strategy to treat this condition. Meticulous preoperative planning is required with thorough multidisciplinary discussion.

\footnotetext{
* Correspondence: o.jarral@imperial.ac.uk

${ }^{2}$ Imperial College, London, UK

${ }^{4}$ Department of Surgery and Cancer, Imperial College London, London W2 INY, UK

Full list of author information is available at the end of the article
}

We report a case of a successful single stage repair of a complex aortic coarctation with concomitant root aneurysm, and aortic valve insufficiency.

\section{Case presentation}

A 44-year old male was referred following investigation for chest pain and dyspnoea. He had no pre-existing co-morbidities. Physical examination revealed feeble femoral pulses and he was found to be hypertensive with marked differences between the upper and lower limbs (systolic blood pressure upper limb $190 \mathrm{mmmHg}$, lower limb $75 \mathrm{mmHg}$, with an ankle brachial index (ABI) of 0.39). Electrocardiogram revealed evidence of severe left ventricular hypertrophy. This was confirmed with echocardiography which also demonstrated a tricuspid aortic valve with significant aortic regurgitation in the presence of an aortic root aneurysm of approximately $9 \mathrm{~cm}$. Left ventricular function was preserved. Computerised tomography angiography (CTA) was performed to evaluate the aortic pathology in further detail (Fig. 1). The scan noted 


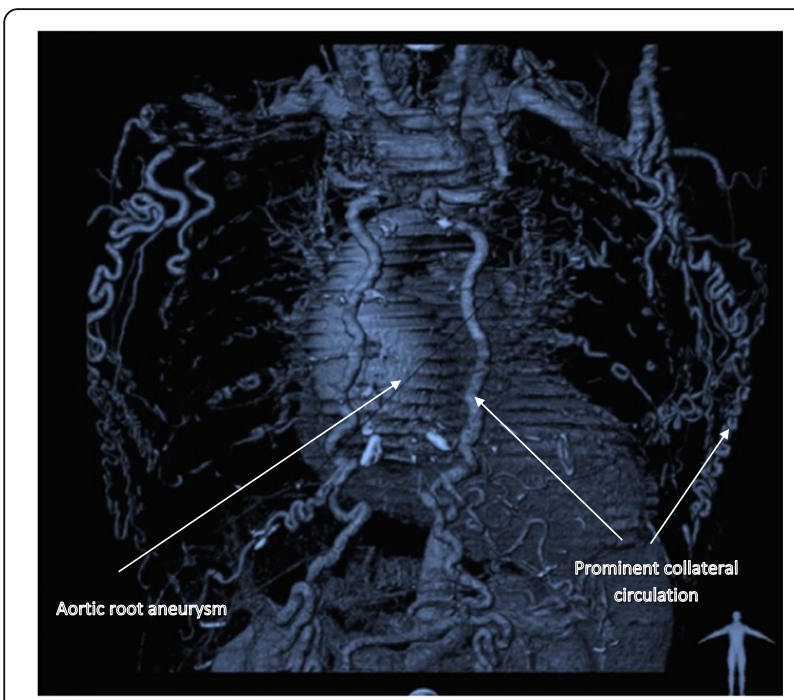

Fig. 1 Computer generated 3D reconstruction of aorta. Demonstrating extensive collateral network

an aortic root aneurysm $(8.8 \mathrm{~cm})$, in addition to the presence of severe aortic coarctation, with subtotal occlusion and a lumen less than $6 \mathrm{~mm}$ in size. The coarctation was just distal to the left subclavian artery, at the aortic isthmus. There was clear evidence of collateral circulation to the descending thoracic aorta via the subclavian and intercostal arteries. Coronary angiography confirmed a right dominant coronary system with no significant coronary disease.

A multidisciplinary team meeting took place and a consensus was agreed to proceed with a two staged hybrid approach, with the first phase involving an endovascular approach to stent the coarctation, followed by a second stage to perform the surgical repair of the aortic root aneurysm. The first stage to stent the coarctation was unsuccessful via the femoral approach, as the guidewire could not cross the coarctation. Assessment through angiography via the left brachial artery showed complete obstruction at the aortic isthmus. The decision was then made to proceed to a single stage surgical approach to treat both lesions.

After induction of anaesthesia, arterial lines were placed in the left radial and left femoral artery. A right infraclavicular incision and a right groin incision was made this was to establish peripheral arterial cannulation access to the right axillary and right femoral artery. An $8 \mathrm{~mm}$ dacron graft was anastomosed to each vessel for indirect cannulation. Median sternotomy was performed to access the mediastinum and expose the heart and aorta. Following heparinisation cardiopulmonary bypass (CPB) was established with venous return from bi-caval cannulation. The body temperature was cooled to 25 degrees Celsius. The right superior pulmonary vein was used for venting. Once the cross clamp was applied, complete cardiac arrest was achieved using Custodiol $25 \mathrm{ml} / \mathrm{kg}$ crystalloid cardioplegia via a retrograde cannula through the coronary sinus. A further top up of cardioplegia was given once the aorta was opened through direct cannulation of the coronary ostia.

The aortic root, valve and ascending aorta were excised. The coronary ostia were fashioned as buttons from the native aortic root. The coronary ostia were noted to be significantly displaced, with distorted anatomy due to the patient's disease process. Therefore, $8 \mathrm{~mm}$ dacron grafts were attached end-to-end to each ostia, with view to performing the modified Cabrol technique later following replacement of the root. The heart was then retracted in a cephalad position to access the posterior pericardium. A vertical incision was made to expose the descending thoracic aorta (DTA). An end to side anastomosis was formed with a $20 \mathrm{~mm}$ dacron graft to the DTA (Fig. 2). This graft was then routed posterior to the inferior vena cava (IVC) and anterior to the right inferior pulmonary vein (RIPV), adjacent to the right atrium (RA). Root replacement was then performed with a $25 \mathrm{~mm}$ biological valved-conduit, as this was favoured by the patient over a mechanical prosthesis, despite the risk of a difficult redo procedure in the future. The $8 \mathrm{~mm}$ dacron grafts attached to the coronary ostia were anastmosed to the root conduit as neo coronary ostia. The distal part of the valved-conduit was anastomosed to the proximal arch under selective antegrade cerebral perfusion (SACP). Finally, an end to side anastomosis was fashioned between the $20 \mathrm{~mm}$ extra-cardiac graft (attached to the descending thoracic aorta) and the ascending portion of the valved-conduit. Valve-sparing root replacement was not

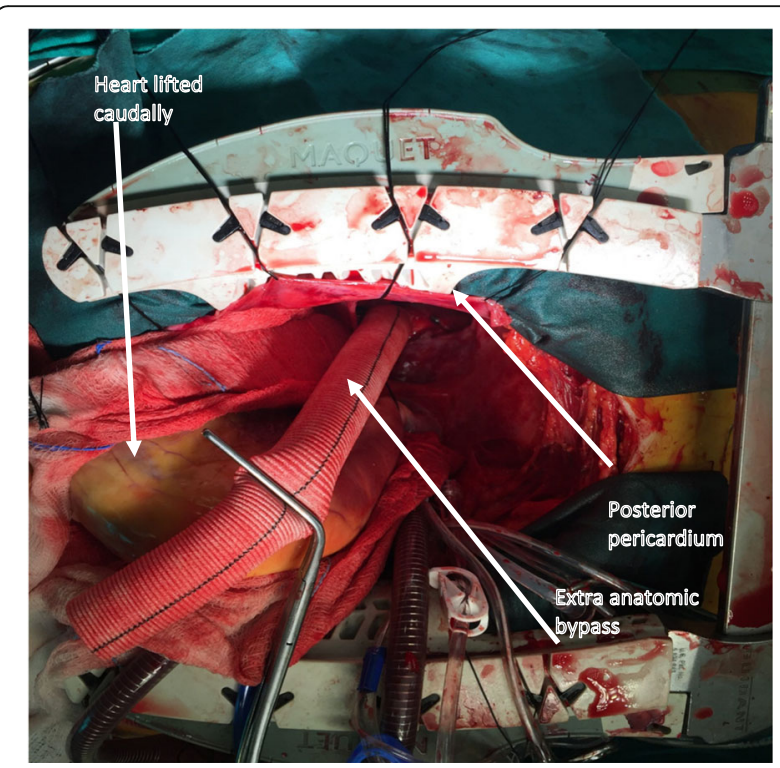

Fig. 2 Surgeons view; longitudinal incision in posterior pericardium to anastomose extra-anatomical bypass to DTA 
considered in this patient due to the grossly abnormal aortic anatomy.

Following rewarming and deairing the patient was successfully weaned off $\mathrm{CPB}$. The bypass time was $160 \mathrm{~min}$, the cross-clamp time was $120 \mathrm{~min}$, and the SACP time was $40 \mathrm{~min}$. Haemostasis was achieved and thereafter a routine closure of all incision sites. The patient remained in ICU for less than $48 \mathrm{~h}$, and made excellent progress on the ward. Minimal anti-hypertensives were required and the patient was discharged on 8th day post operatively neurologically intact and independent. At 3 months follow up the patient underwent a repeat CTA scan which showed complete patency in the extra-anatomical graft and resolution of the collateral arterial network (Fig. 3).

\section{Discussion}

Aortic coarctation is a common congenital cardiac defect, with narrowing of the aorta at the isthmus. The condition is generally identified and treated during infancy and childhood. However presentation of untreated aortic coarctation in adults with associated cardiac defects are scarcely reported [3, 4].

In this complex case we treated three distinct lesions (aortic root aneurysm, aortic valve insufficiency and aortic coarctation) through a single staged approach. An additional challenge encountered was the reimplantation of the coronary buttons. The aortic root aneurysm was of a significant size, hence reimplantation of the coronary ostia directly on to the neo aorta was not possible as the coronary arteries would be overstretched. The use of the modified Cabrol technique was incorporated into this single staged operation to provide safe implantation of the coronary buttons with a tension free anastomosis
[5]. We believe this is the first reported case where the modified Cabrol technique has been used in this setting.

There remains a wide range of treatment options for aortic coarctation which can be broadly divided into surgical and non-surgical strategies. Non-surgical interventional techniques are becoming increasingly popular, either with balloon angioplasty and or insertion of a stent. These approaches can be used both in native and recurrent disease. However, there is insufficient long-term data available in comparing these interventions with surgical repair. Although these approaches are often associated with lower morbidity compared to surgery, there is an increased rate of re-stenosis $11 \%$ versus $2 \%[6,7]$ hence a higher need for reintervention. Reintervention may also be required due to stent fracture, migration and possible aneurysm formation. Careful patient selection is required as not all cases are amenable to percutaneuous intervention. Our patient underwent an interventional approach initially, however the guidewire was unable to cross the lesion.

Surgical repair can include the option of primary repair of the coarctation, either through a left thoracotomy (2-stage repair when in the presence of other cardiac defects) or median sternotomy. However, this is associated with many challenges especially in the adolescent and adult patient population. Extensive mobilisation of the aorta is required, in addition to control of the extensive collateral blood vessels this can contribute to increased risk of bleeding. Other complications can include possibility of lung parenchymal injury, damage to the recurrent laryngeal and or phrenic nerves, chylothorax and the possibility of spinal cord ischaemia [8]. Due to these many risks primary anatomic repair of the coarctation has been avoided in adult patients.

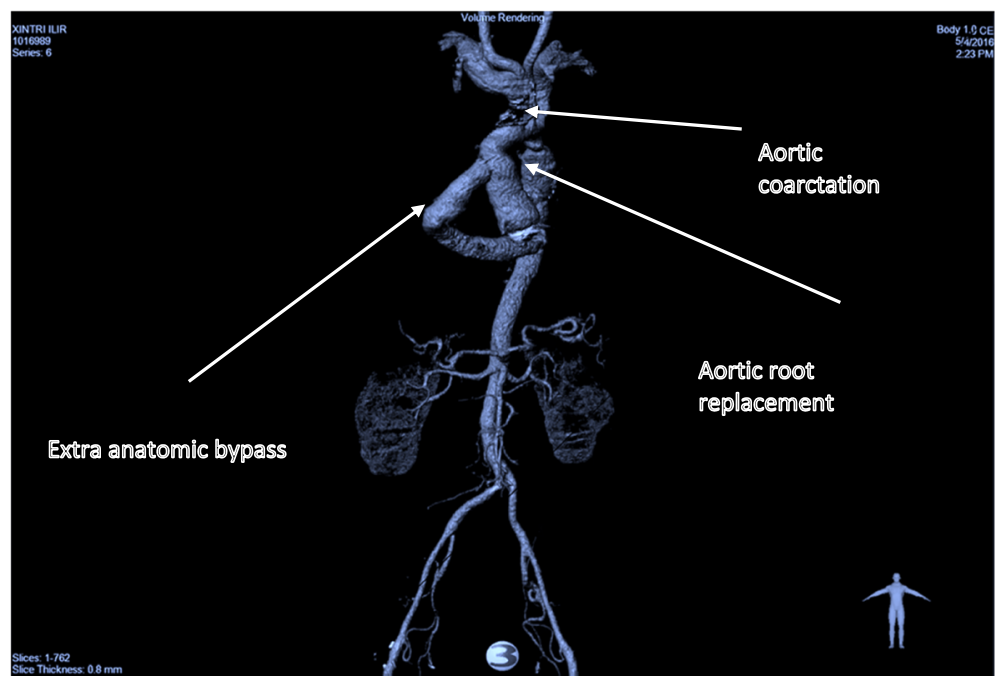

Fig. 3 Computer generated 3D reconstruction demonstrating surgical repair 
In attempt to reduce complexity of open surgical repair, variations of extra-anatomic bypass have been developed. The single stage procedure was first described by Vijayanagar and colleagues in 1980 [9]. The procedure incorporated an extra-anatomic bypass from the ascending aorta to the DTA through the posterior pericardium. This operation allowed bypass of the coarctation in addition being able to correct other concomitant cardiac defects, i.e. valve replacement, in a single staged approach [8]. This strategy is also preferred in cases where there is a complex coarctation or re-coarctation where a primary repair would be associated with major complications as described above. In addition to the major benefit of being able to treat multiple cardiovascular disorders at the same time in one sternotomy, there is no need for laparotomy to reach the DTA, and the graft is routed in a short course around the right margin of the heart without the risk of compressing the right atrium or ventricle [8].

The initial procedure by Vijayangar described routing the extra anatomic bypass around the left lateral border of the heart. Powell et al. modified this procedure by positioning the graft along the right sided margin of the heart, the benefit being that the graft remains in a more posterior position hence allowing safer re-entry into the chest if reoperation is required [8]. In addition positioning the graft anterior to the RIPV and behind the IVC prevents compression to the right atrium and ventricle [10]. The possible difficulties in this procedure are that accessing the DTA through the posterior pericardium is difficult and exposure maybe more challenging in patients who are obese or have a barrel shaped thorax. The procedure may not be suited to patients in the adolescent group due to their potential somatic growth that could lead to anastomotic dehiscence. Potential long term complications that have been described with this procedure include narrowing of the graft, neointimal thrombus formation, pseudoaneurysm formation or anastomotic dehiscence in patients with who have had somatic growth since their initial procedure. However, in a paper by Connolly et al. [8] with a mean follow up of 3.7 years there were no complications in patients who underwent single stage surgical treatment.

\section{Conclusion}

When coarctation or re-coarctation is associated with cardiac defects that require repair, a single stage approach using cardiopulmonary bypass and coarctation bypass grafting through the posterior pericardium is a safe surgical alternative, as demonstrated by this case. We understand this is also the first reported case where the modified Cabrol technique has been incorporated with this single staged procedure to treat aortic root aneurysm and aortic coarctation. The surgical management of patients with complex coarctation or recoarctation with or without associated cardiac disorders must be individualised and treatment options should be discussed in an open multidisciplinary platform.

Extra-anatomic coarctation bypass is a safe alternative method when endovascular interventions are not feasible. Particular attention must be paid to ensuring the extra-anatomic bypass conduit is well positioned and of a significant calibre. Kinking of this conduit can lead to turbulent blood flow and abnormal wall shear stress which could impact on long term patency. We felt that routing the extra-anatomic bypass posterior to the IVC achieved the best haemodynamic result.

Our strategy has proved to be particularly useful in an adult patient where simultaneous intra cardiac repair is required.

\section{Abbreviations \\ ABI: Ankle brachial pressure index; CPB: Cardiopulmonary bypass; CTA: Computerised tomography angiography; DTA: Descending thoracic aorta; ICU: Intensive care unit; IVC: Inferior Vena Cava; RIPV: Right inferior pulmonary vein; SACP: Selective antegrade cerebral perfusion}

\section{Authors contributions}

TA conceived the report. $\mathrm{YI}$ and $\mathrm{OJ}$ wrote the first draft with input from all authors. All authors approved the final manuscript.

Ethics approval and consent to participate Not applicable.

\section{Consent for publication}

Consent for publication of this case report in its entirety was obtained from the patient.

\section{Competing interests}

The authors declare that they have no competing interests.

\section{Publisher's Note}

Springer Nature remains neutral with regard to jurisdictional claims in published maps and institutional affiliations.

\section{Author details}

${ }^{1}$ Birmingham Children's Hospital, Birmingham, UK. ' Imperial College, London, UK. ${ }^{3}$ Evangelismos Hospital, Athens, Greece. ${ }^{4}$ Department of Surgery and Cancer, Imperial College London, London W2 1NY, UK.

Received: 20 February 2018 Accepted: 15 June 2018

Published online: 22 June 2018

\section{References}

1. Kenny D, Hijazi ZM. Coarctation of the aorta: from fetal life to adulthood. Cardiol J. 2011;18(5):487-95.

2. Quennelle S, Powell AJ, Geva T, Prakash A. Persistent aortic arch hypoplasia after Coarctation treatment is associated with late systemic hypertension. J Am Heart Assoc. 2015:4(7)

3. Bigdeli AK, Schmitz C, Kaczmarek I, Schmauss D, Wintersperger B, Reichart B, et al. Combined aortic valve replacement and extra-anatomic aorta ascending-descending bypass for recurrent aortic coarctation. Ann Thorac Surg. 2010;89(4):e22-4.

4. Okita Y, Takanashi S, Fukumura Y. Simultaneous cusp-sparing aortic root replacement and coarctectomy with total arch replacement from the midline incision. Interact Cardiovasc Thorac Surg. 2014;19(1):166-8.

5. Kourliouros A, Soni M, Rasoli S, Grapsa J, Nihoyannopoulos P, O'Regan D, et al. Evolution and current applications of the Cabrol procedure and its modifications. Ann Thorac Surg. 2011;91(5):1636-41.

6. Forbes TJ, Gowda ST. Intravascular stent therapy for coarctation of the aorta. Methodist Debakey Cardiovasc J. 2014;10(2):82-7. 
7. Carr JA. The results of catheter-based therapy compared with surgical repair of adult aortic coarctation. J Am Coll Cardiol. 2006;47(6):1101-7.

8. Connolly HM, Schaff HV, Izhar U, Dearani JA, Warnes CA, Orszulak TA. Posterior pericardial ascending-to-descending aortic bypass: an alternative surgical approach for complex coarctation of the aorta. Circulation. 2001; 104(12 Suppl 1):1133-7.

9. Vijayanagar R, Natarajan P, Eckstein PF, Bognolo DA, Toole JC. Aortic valvular insufficiency and postductal aortic coarctation in the adult. Combined surgical management through median sternotomy: a new surgical approach. J Thorac Cardiovasc Surg. 1980;79(2):266-8.

10. Izhar U, Schaff HV, Mullany CJ, Daly RC, Orszulak TA. Posterior pericardial approach for ascending aorta-to-descending aorta bypass through a median sternotomy. Ann Thorac Surg. 2000;70(1):31-7.

Ready to submit your research? Choose BMC and benefit from:

- fast, convenient online submission

- thorough peer review by experienced researchers in your field

- rapid publication on acceptance

- support for research data, including large and complex data types

- gold Open Access which fosters wider collaboration and increased citations

- maximum visibility for your research: over $100 \mathrm{M}$ website views per year

At BMC, research is always in progress.

Learn more biomedcentral.com/submissions 